\title{
Expectativas profissionais de alunos de camadas populares: apontamentos sobre o papel da escola pública estadual ${ }^{1}$
}

André Wiliam de Novais da Costa²

Tiago Magaldi ${ }^{3}$

\begin{abstract}
Resumo:
O presente trabalho investiga o papel da escola na produção de expectativas profissionais e educacionais de seus alunos. A partir do mapeamento das perspectivas de futuro de jovens do terceiro ano do ensino médio de uma escola pública estadual do Rio de Janeiro, realizado por meio de instrumento do tipo survey, bem como entrevistas em profundidade, apontamos como os próprios alunos elaboram acerca das oportunidades para atingir seus objetivos escolares e profissionais. Chega-se à conclusão de que os alunos incorporam o desejo de trajetórias plausiveis para eles, reafirmando os achados da "teoria da reprodução", mas, longe da resignação, desenvolvem estratégias de ascensão, das quais a escolha pelo militarismo é a melhor ilustração, por sua aparência de estabilidade remuneratória e garantia de manutenção do vínculo "empregatício", elementos percebidos como cruciais para as estratégias de ascensão profissional. Para sustentar esta interpretação mobilizamos não apenas autores que tomaram exclusivamente a escola por objeto, mas também os que o fizeram para o trabalho e a política, vez que tratamos aqui da produção social de expectativas de acesso a bens. Nesse sentido, o artigo se situa, teoricamente, nas fronteiras das sociologias da educação, do trabalho e da política.
\end{abstract}

\section{Palavras-chave:}

Jovens. Ensino médio. Desigualdades escolares. Expectativas profissionais.

\section{Professional expectations of students from lower classes: notes on the role of the state public school}

\footnotetext{
Abstract: The present work investigate role of the school in the production of professional and educational expectations of its students. Based on the mapping of the future perspectives of young people in the third year of high school at a state public school in Rio de Janeiro, carried out using a survey-type instrument, as well as in-depth interviews, we point out how the students themselves currently elaborate opportunities to achieve their professional goals. We conclude that students incorporate the

10 presente trabalho foi realizado com apoio da Coordenação de Aperfeiçoamento de Pessoal de Nível Superior - Brasil (CAPES) - Código de Financiamento 001.

2 Mestrando do Programa de Pós-Graduação em Educação da UERJ. E-mail: andre.wcosta@yahoo.com.br. ORCID iD: http://orcid.org/0000-0003-4094-8923.

3 Doutorando em Sociologia na Universidade Federal de São Carlos (UFSCar). E-mail: tmgranato@gmail.com. ORCID iD: http://orcid.org/0000-0001-7498-0492.
} 
desire for plausible trajectories for them, reaffirming the findings of the "theory of reproduction", but, far from resignation, they develop ascension strategies, of which the choice for militarism is the best illustration, for its apparent stability in remuneration and assurance of a "work" position, crucial elements for the strategies of professional ascent. In order to sustain this interpretation we mobilize not only authors who took the school as an object, but also those who did that on work and on politics, since we deal here with the social production of expectations of access of goods. In this sense, the article is situated, theoretically, on the borders of the sociologies of education, of work and political sociology.

Keywords: Youth. High school. School inequalities. Professional expectations.

\section{Expectativas profesionales de los estudiantes de clases bajas: notas sobre el papel de la escuela pública estatal}

Resumen: El presente trabajo investiga el papel de la escuela en la producción de expectativas profesionales y educativas de sus alumnos. A partir del mapeo de las perspectivas de futuro de los jóvenes de tercer año de secundaria en una escuela pública estatal de Río de Janeiro, realizado a través de un instrumento tipo encuesta, así como entrevistas en profundidad, señalamos cómo los estudiantes ellos mismos elaboran actualmente sobre las oportunidades para lograr sus objetivos profesionales. Concluimos que los estudiantes incorporan el deseo de trayectorias plausibles para ellos, reafirmando los hallazgos de la "teoría de la reproducción", pero, lejos de la resignación, desarrollan estrategias de ascensión, de las cuales el militarismo es el mejor ejemplo, por su aparente estabilidad remunerativa y por la garantía de un vínculo de empleo, elementos cruciales para las estrategias de subida profesional. Para sustentar esta interpretación nosotros movilizamos no sólo autores quienes han tomado la escuela por objeto, pero también aquellos quienes lo hicieran para lo trabajo e para la política, puesto que tratamos acá con la producción social de expectativas de acceso a bienes. En este sentido, el artículo está situado, teóricamente, en las fronteras de las sociologías de la educación, del trabajo, y de la política.

Palabras clave: Juventud. Escuela secundaria. Desigualdades escolares. Expectativas profesionales.

\section{Introdução}

Ao comentar a plausibilidade de movimentos sociais contra a enorme desigualdade social no Brasil - desigualdade cuja existência é reconhecida pela maioria da população do país (CARDOSO, 2004) -, Wanderley Guilherme dos Santos (2006) afirma que os custos de mobilização seriam altos demais para as camadas menos favorecidas. Esta inércia conservadora implicaria, no decorrer do tempo, em um rebaixamento do horizonte de expectativas sociais das camadas populares. É a partir desse diagnóstico mais geral acerca da dinâmica social brasileira, bastante presente na reflexão sociológica brasileira, que perguntamos: qual seria o papel da escola pública na adoção, por alunos de ensino médio, de horizontes de expectativas educacionais e profissionais? Até que ponto realmente há uma escolha de perspectivas? O presente trabalho tem como objetivo contribuir para a investigação empírica dessa problemática.

Partindo do mapeamento das perspectivas de futuro de dezenas de jovens do terceiro ano do ensino médio de uma escola pública estadual do Rio de Janeiro, realizado por meio de dois instrumentos, um do tipo survey, e entrevistas em profundidade com uma dezena de alunos, além de uma análise do próprio cenário escolar no qual se desenvolvem as interações pedagógicas, apontamos, seguindo a trilha de Scalon e Oliveira (2012), como os próprios alunos pensam a produção de oportunidades para atingir seus objetivos profissionais. Além das informações acerca de suas expectativas, 
foram coletados dados que compõem um perfil socioeconômico e das percepções dos jovens acerca do ambiente escolar em si, procurando articular técnicas de pesquisa quantitativa e qualitativa.

Em tempos de pandemia global, profissionais da educação, pais, alunos e formuladores de políticas públicas debatem vivamente o impacto da crise da saúde pública no desempenho e, consequentemente, no futuro dos alunos. Neste momento, torna-se ainda mais explícita a distribuição diferencial de oportunidades não apenas de entrada em universidades e/ou profissões valorizadas, mas das próprias "expectativas" de entrada em ambos os universos. Assim, este trabalho se justifica ao perscrutar o cada vez mais pertinente tema das desigualdades sociais e escolares, que procuramos tratar aqui tanto em termos "objetivos" quanto "subjetivos", isto é, articulando possibilidades reais de inserção universitária e profissional e as expectativas de alunos de escolas públicas estaduais quanto a elas.

Num momento de transformações no mundo do trabalho, cujo maior símbolo no país, nos últimos anos, foi a Reforma Trabalhista ${ }^{1}$ (KREIN, 2018), mas também de modo geral com o processo de longa duração da precarização do trabalho (ANTUNES, 2018) e do aumento do desemprego e trabalho informal, como as perspectivas do aluno são afetadas? O que eles esperam e o que os espera quando saírem da escola? Devem pensar no que gostariam de fazer ou no que há disponível no mercado de trabalho? Qual o impacto da escola nessa produção ou ruptura de expectativas?

Além de suas próprias percepções, há o peso da expectativa de pais, responsáveis e professores sobre o que esses jovens são e fazem e o que eles representam. Numa fase de experimentações, como é a adolescência, estes jovens muitas vezes são estigmatizados e marcados por diversos fatores. Como expõe Dayrell (2007), a juventude é vista como um "vir a ser" - não se considera o que o jovem é naquele momento, mas sim como está sempre em formação para ser alguém no futuro. Portanto, ele parece sempre carregar um vazio, uma carência, anulando suas contribuições, suas ideias e pensamentos. Por fim, vê sua diversidade e individualidade sempre em risco ao ser encaixado indistintamente na categoria "jovem".

A escola e seus componentes também foram afetados pela pandemia que vivenciamos, e algumas reflexões se tornaram ainda mais necessárias. Ficou publicamente evidente a clara distância entre os alunos da rede pública e os da rede privada de ensino. No momento em que a escola é temporariamente transferida para plataformas digitais, a desigualdade se escancara. Desde ter computador e planos de internet até um espaço reservado para o estudo, esses fatores acabam por distanciar ainda mais quem tem possibilidade de continuar estudando e se preparando para quem não pode.

Como coloca Geraldi (2015), quando define a divisão do trabalho social do trabalho educativo, o professor assume uma posição de executor e o aluno de receptáculo. O material didático se torna o fator mais importante na escola, e o professor, mero transmissor do conhecimento. $\mathrm{O}$ "cuidado de si" torna-se responsabilidade exclusiva do aluno. Daí mais uma vez vemos reforçada a reprodução das desigualdades, com a culpabilização dos alunos e das famílias pelo sucesso ou fracasso escolar dos mesmos, gerando uma naturalização do fracasso escolar de alguns alunos: eles não "caberiam" na escola, não "serviriam" para o estudo. A expansão do neoliberalismo enquanto não só uma doutrina econômica, mas um projeto de disciplinamento da subjetividade dos indivíduos sob a égide da "concorrência", da luta de todos contra todos no mercado (DARDOT; LAVAL, 2017), produziu um cenário de competição, inclusive nas periferias, e responsabilização individual do aluno por não aproveitar as "oportunidades" de ascender socialmente oferecidas pela escola ${ }^{2}$.

\footnotetext{
1 Nome pelo qual ficou conhecida a Lei 13.467/2017, sancionada em 13 de julho de 2017, que realizou uma mudança significativa na Consolidação das Leis Trabalhistas (CLT) em um sentido pró-mercado, isto é, reduzindo as proteções legais e os direitos dos trabaIhadores. Para uma ampla avaliação crítica da Reforma, ver CESIT (2017) e Filgueiras (2019).

2 No dia 5 de maio de 2020, em uma reunião, o atual Ministro da Educação disse não haver motivos para adiamento do Enem e afirma que o mesmo não foi feito para corrigir injustiças. Dessa maneira, o Enem se torna mais uma ferramenta de aprofundamento das desigualdades sociais, já que alunos impossibilitados de se preparar para o vestibular vão disputar com uma minoria que pôde se preparar. https://www1.folha.uol.com.br/educacao/2020/05/em-reuniao-com-senadores-weintraub-diz-que-enem-nao-foi-feito-para-corrigir-injusticas.shtml?origin=folha.
} 
O artigo será desenvolvido como se segue: primeiramente, apresentaremos a produção dos dados utilizados na análise. Na seção seguinte apresentaremos o perfil dos alunos que os dados quantitativos nos permitiram delinear e, depois, uma análise das entrevistas em profundidade. Logo após virá uma seção desenvolvendo nosso argumento principal e, por fim, as considerações finais.

\section{Da produção dos dados}

Partiremos de dois conjuntos de dados: 1) dados quantitativos sobre os alunos de uma escola produzidos através de um instrumento de tipo survey; 2) entrevista em profundidade com dez alunos selecionados a partir das respostas ao questionário.

O questionário foi aplicado a três turmas de terceiro ano do ensino médio no ano de 2017. Era composto de 33 perguntas: as primeiras faziam parte de um bloco socioeconômico, outra parte tratava da relação do aluno com a escola e suas disciplinas; por fim, um bloco sobre a perspectiva profissional do aluno ao concluir a escolaridade básica e sobre as políticas de acesso ao ensino superior.

Os questionários foram aplicados em dias diferentes do mês de novembro no turno matutino, com alunos de idades que variam entre 16 e 20 anos, e que cursam o ensino médio regular. São turmas compostas por quantidades diferentes de alunos, bastante diversas no que diz respeito à idade, etnia, desempenho escolar, e nem todas têm professores de todas as disciplinas. Os alunos são enturmados aleatoriamente. A aplicação foi realizada presencialmente com os alunos que haviam comparecido à escola no dia de sua realização. Como eram alunos para os quais lecionamos ao longo do ano e, sabendo que nossa presença em sala poderia influenciar as respostas, foram tomados alguns cuidados, como orientá-los sobre a fidelidade das respostas, sem se preocupar em tentar responder "corretamente". Foi explicado qual era o propósito do questionário, com uma breve explanação sobre a pesquisa, tendo sido necessário solucionar eventuais dúvidas, pois eles nunca haviam respondido a um questionário deste tipo. Ao fim do processo alguns alunos afirmaram ter gostado de participar da experiência e disseram sentir que estavam participando de algo importante.

As respostas apresentaram cinco diferentes perspectivas sobre o que fazer após a conclusão do ensino médio: 1) cursar uma universidade pública; 2) cursar uma universidade privada;3) entrar no ensino técnico; 4) entrar em escolas militares e 5) ir para o mercado de trabalho. Para as entrevistas em profundidade foram escolhidos 2 alunos que haviam escolhido cada uma dessas opções, totalizando 10 alunos. Pensamos ser um número suficiente de entrevistas naquele momento para aprofundar os questionamentos e reflexões sobre as escolhas e a escola. Outra preocupação foi a de ter um aluno e uma aluna dentro de cada dupla, buscando minimizar algum viés de gênero. Foram, assim, entrevistados cinco alunos e cinco alunas. Para a escolha daqueles que fariam parte deste momento da entrevista, foram selecionados, dentre os que tinham o perfil desejado, em função de gênero e do que pretendiam para o futuro, aqueles que tinham disponibilidade para a entrevista. É importante deixar claro que, dentro deste grupo de 10 estudantes, alguns falaram na necessidade de trabalhar no ano seguinte, principalmente para conseguir pagar algum curso preparatório ou a faculdade, o que os colocaria todos na quinta perspectiva de futuro apontada acima, o da entrada no mercado de trabalho. A constatação dessa ambiguidade, que poderia introduzir vieses interpretativos, nos fez escolher para compor a categoria "mercado de trabalho", apenas o par de alunos que mencionou exclusivamente essa categoria como opção.

As entrevistas com os dez alunos seguiram um roteiro semiestruturado que tinha como objetivo um depoimento mais detalhado e aprofundado daqueles alunos sobre o objeto da pesquisa. O roteiro estava dividido em perguntas sobre a experiência no ensino médio, impressões sobre o ensino e suas perspectivas e escolhas, perspectivas de futuro e as estratégias para alcançá-las. As entrevistas foram individuais, realizadas em novembro e dezembro de 2017. 


\title{
Perfil socioeconômico e percepções de trajetória dentre os alunos
}

\author{
Perfil socioeconômico e expectativas: dados quantitativos
}

O Colégio Estadual João da Silva ${ }^{3}$ possuía naquele momento 1026 alunos matriculados no ensino médio (520 no primeiro ano, 280 no segundo ano e 226 no terceiro ano) e 202 no ensino de jovens e adultos, além de 5 na educação especial. Ali trabalham 93 funcionários ao todo. É localizado em Senador Camará, bairro da Zona Oeste do Rio de Janeiro.

Um primeiro dado importante é relativo à distorção série-idade. No ano de 2016, juntando todas as turmas do ensino médio, 37\% dos alunos estavam com atraso escolar de 2 anos ou mais. No primeiro ano se encontram as maiores taxas de distorção: $44 \%$ dos alunos estavam com atraso escolar de 2 anos ou mais, seguidos do segundo ano com um percentual de $30 \%$ e do terceiro ano com $28 \%$. Quanto às taxas de rendimento dos alunos do colégio por ano do ensino médio, no primeiro ano também estão os maiores casos de reprovação e abandono, em que um pouco mais metade dos alunos (52,7\%) foi aprovada ${ }^{4}$.

Quanto ao perfil socioeconômico, delineado já a partir dos dados levantados pelo questionário que aplicamos, verificamos que $90 \%$ dos alunos têm casa própria, sendo o restante residente em imóvel alugado; $65 \%$ declararam ter um banheiro em casa, enquanto $31 \%$ têm dois, e $4 \%$ têm três ou mais. Quanto ao número de cômodos na casa, $7 \%$ dos alunos declararam morar numa de dois cômodos, 41,5\% marcaram a opção de três cômodos, $23 \%$ marcaram a de quatro cômodos e, por fim, $24 \%$ declararam que moram numa casa com mais de quatro cômodos. Essas informações se encontram resumidas no Gráfico 1, abaixo:

Gráfico 1 - Dados Socioeconômicos

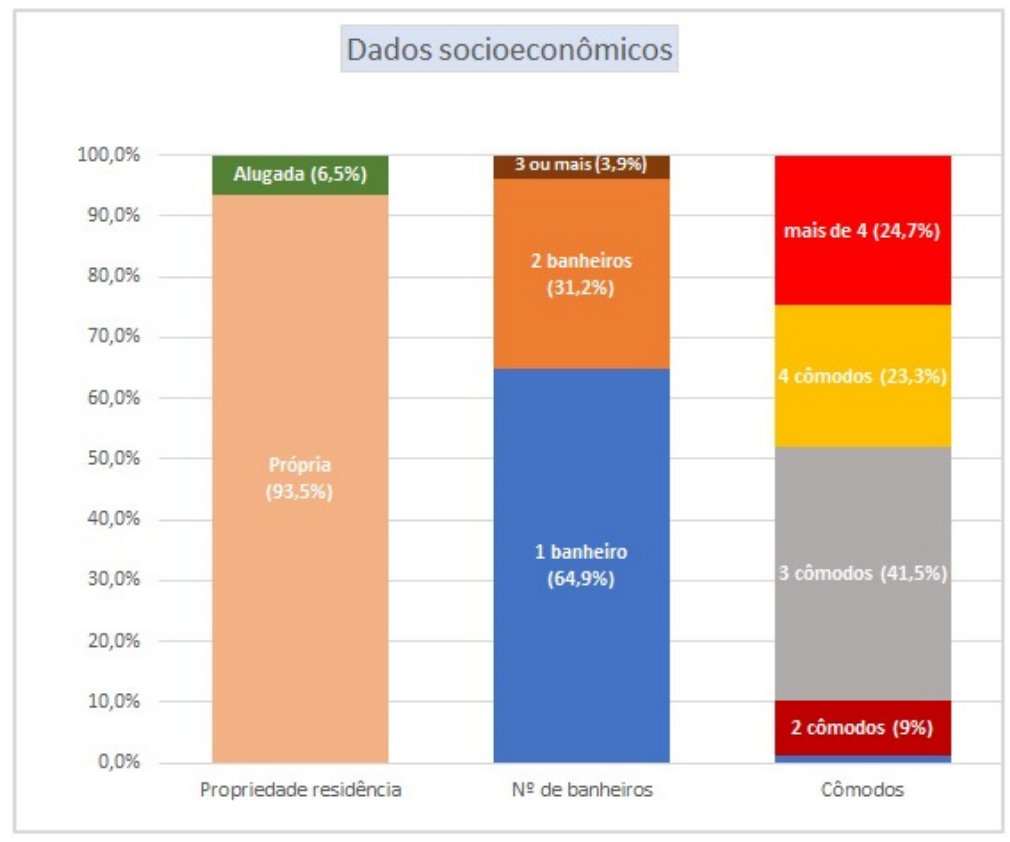

Fonte: Elaborado pelo autor.

Em relação às expectativas para o ano seguinte ao término da escola, 20\% pensavam em se dedicar a um curso preparatório enquanto trabalhavam como civis ou militares; $17 \%$ dos alunos responderam esperar serem aprovados e estar em uma universidade, pública ou privada, ao mesmo

3 Nome fictício.

4 Nome fictício. Informações em: www.qedu.org.br. 
tempo em que trabalhariam; $16 \%$ esperavam estar exclusivamente estudando em uma universidade, pública ou privada; $14 \%$ procuravam exclusivamente uma carreira militar; $13 \%$ pretendiam estar apenas trabalhando; $8 \%$ gostariam de partir para o ensino técnico; e 7\% pensavam em se dedicar exclusivamente a um curso preparatório para, no ano seguinte, tentar uma vaga numa universidade ou numa escola militar. Estes dados se encontram no Gráfico abaixo:

Gráfico 2 - Expectativas para o ano seguinte

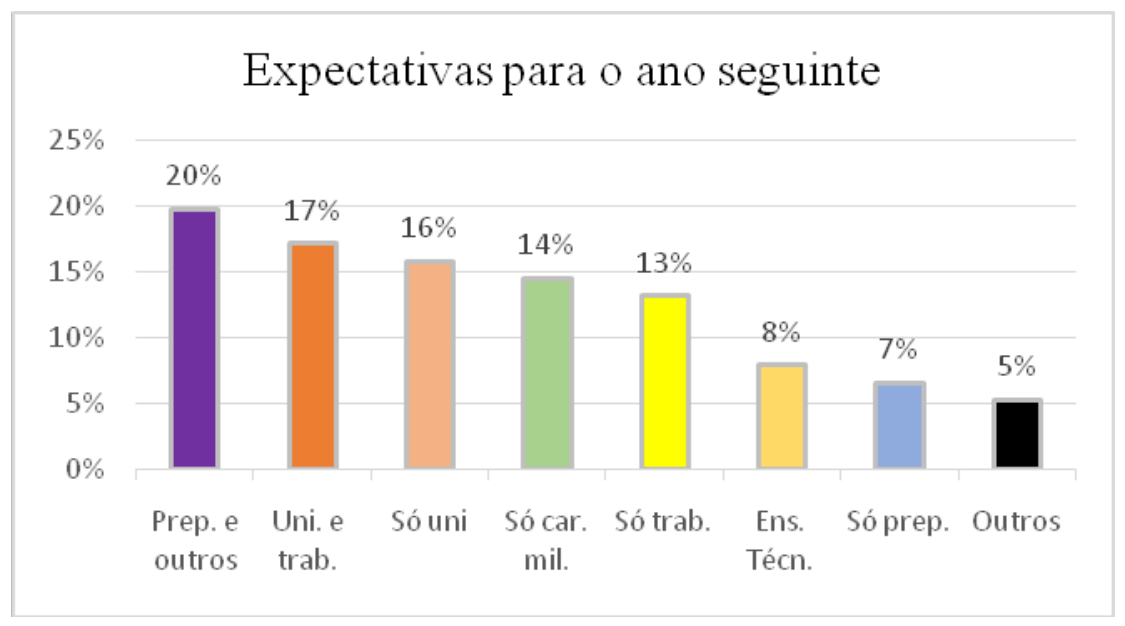

Fonte: Elaborado pelo autor.

Mais de $80 \%$ dos alunos responderam que o principal motivo para desejarem trabalhar era o de ter renda própria. Apenas $10 \%$ dos alunos optaram pela opção "contribuir com a renda da casa". Esta é uma informação muito relevante para refletirmos sobre o processo de saída da escola dos alunos do ensino público estadual, momento no qual o jovem se vê muitas vezes sem perspectivas sobre o próximo passo a ser dado. Ele tende a se defrontar com perguntas acerca de seu destino pessoal e profissional, questões estas cruciais para ele, e diante das quais a escola teria de contribuir de alguma forma - no mínimo, na sua problematização (DAYRELL; LEÃO; BATISTA, 2011, p. 257).

Mas, na verdade, muitos jovens passam pela escola e saem dela sem uma orientação e esclarecimento sobre que caminhos seguir:

Parece-nos que a escola não vem possibilitando uma formação humana mais ampla de seus jovens, de tal forma a contribuir para uma compreensão de si mesmos, das suas habilidades e desejos, bem como da realidade onde se inserem, com uma visão sobre o mundo do trabalho e suas demandas e exigências. No momento decisivo de escolhas de possíveis rumos de vida, parece que a escola pouco contribui para um conhecimento do que a universidade pode ou não oferecer, os cursos existentes com suas especificidades e demandas próprias. (DAYRELL; LEÃO; BATISTA, 2011, p. 270).

Quanto à formação do principal responsável, apenas $5 \%$ tinham ensino superior, sendo que desses só um trabalhava na sua área. Cerca de metade concluiu o ensino médio, $27 \%$ completou o segundo segmento do ensino fundamental, com outros $10 \%$ tendo estudado da 1a à 4a série. Portanto, se ingressarem no ensino superior, a grande maioria desses alunos serão os primeiros de sua família a fazê-lo. O ingresso numa universidade ainda não é algo frequente se levarmos em consideração os caminhos tomados dentro de suas famílias. É o que também observa Dayrell, em pesquisa realizada no estado do Pará:

A grande maioria dos jovens pesquisados apresentava uma escolaridade maior do que a de seus pais, reflexo da expansão do ensino médio no Pará e no Brasil, conforme vimos anteriormente. Ou seja, encontram-se inseridos em uma família com pouca tradição escolar, o que interfere nas suas trajetórias. (2011, p. 259). 
Contrariando o que intuíamos ao iniciar a produção empírica, pela conversa com os alunos e por observar alguns deles chegando com seus uniformes de Jovem Aprendiz, a maioria não trabalha. Mais de $80 \%$ dos entrevistados não estavam trabalhando no momento do questionário. Alguns já trabalharam antes, como o aluno que colocou como profissão a seguir a carreira de jogador de futebol. Ele foi um dos poucos a eleger como sua expectativa somente o trabalho, tendo já trabalhado como jogador de futebol durante cinco anos. Não tem interesse no momento em continuar seus estudos, mas gosta de ir à escola; a principal razão para isso é a expectativa de conseguir um emprego melhor.

Corroborando com o discurso de alguns alunos entrevistados, $34 \%$ dos alunos responderam à pergunta sobre qual estratégia era utilizada na preparação para seu objetivo futuro com a opção "estudo para ser aprovado nas disciplinas do colégio". Já outros $24 \%$ declararam "estudar por conta própria além das exigências da escola". 6,5\% dos alunos disseram se utilizar dessas duas estratégias, e outros $13 \%$ disseram fazer um curso preparatório. Mas surpreende o número de alunos (18\%) que não marcaram nenhuma opção, indicando que não estão se preparando para seus objetivos, sejam eles quais forem.

A maioria dos alunos respondeu conhecer pelo menos uma das políticas de ação afirmativa. Dos entrevistados, 17\% declararam conhecer todas as opções fornecidas (cotas; ProUni; Fies; Sisu; Pronatec). Outros $16 \%$ disseram só conhecer a política de cotas, enquanto 9\% o ProUni, 5\% o Fies e outros $5 \%$ o Sisu. O Pronatec também ganha destaque, com 13\% declarando conhecê-lo. Apenas 3\% dos alunos não conheciam nenhuma das políticas mencionadas na questão.

Em relação à utilização de políticas de ação afirmativa ou programa do governo de acesso ao ensino superior, a mais escolhida (por 17\%) foram as cotas. Outros 15\% vão se utilizar do ProUni, e $14 \%$ do Pronatec. Fies e Sisu serão utilizados, cada um, por $8 \%$ dos alunos, o que é de se estranhar, tendo em vista que todos que farão o Enem terão que se inscrever no Sisu. Porém esses números podem apontar justamente o desconhecimento sobre essa etapa no acesso ao ensino superior. Por fim, 15\% disseram que não pretendem se utilizar de nenhuma dessas políticas.

\section{O rebaixamento de expectativas e a busca da estabilidade financeira}

Nas entrevistas, os alunos não demonstraram muito conhecimento acerca da diferença entre uma universidade pública ou privada. É o caso de uma entrevistada, Paula ${ }^{5}$, que escolheu o curso de Jornalismo, e que disse ter como objetivo ganhar algum dinheiro com a profissão, que seria sua paixão. Não teria preferência por cursar uma faculdade pública ou privada; ela diz não conhecer as diferenças, mas já escutou outras pessoas dizerem que a pública seria melhor. Terminou o ensino médio sem expectativa de ser aprovada numa universidade pública por não ter ido muito bem na escola.

A questão financeira é uma preocupação muito presente, não só no discurso apresentado pelos alunos nas entrevistas, mas também nos questionários. E notamos que aqueles que têm como horizonte a vida militar mencionam sempre a "estabilidade financeira" desta carreira. Nesse sentido, a vida militar aparenta ser uma boa opção na opinião de alguns alunos, principalmente para aqueles que já têm militares na família.

Renata, que tem dois irmãos militares, é uma aluna que pensa desta forma. Já fazendo um curso de Técnico de Enfermagem concomitante ao terceiro ano, ela argumenta que o meio militar é o único que vai permitir que ela trabalhe nesta área recebendo seu salário sem riscos. Não tentou as provas no ano da entrevista porque não se considerava preparada. Para o ano seguinte planejava fazer um curso para tentar uma vaga na Marinha, mas ainda não sabia como iria pagar o curso, pois todos de sua família trabalhavam, inclusive ela, e na época esta não era uma despesa que poderiam arcar.

5 Todos os nomes aqui utilizados são fictícios. 
O aluno Júlio, assim como Renata, também escolheu o caminho militar. Já havia tentado a prova para oficial do Exército em 2017, porém não passou por causa de uma questão de história. E afirmava que ano que vem continuaria seu preparo, fazendo um curso preparatório e sendo mais organizado em suas tarefas. Os dois também falaram sobre cursar uma universidade futuramente, após a entrada numa escola militar.

Na verdade, eu busco o militarismo como forma de estabilidade, entende? Busco uma independência acima de tudo. Ficar livre de pai e mãe. Poder cursar uma boa faculdade futuramente com um salário legal. Saber que vai ter um salário fixo todo mês. (Júlio).

Já em relação a se o ensino da escola seria suficiente para alcançar esses objetivos, Renata e Júlio pensavam diferente. Ela e a maioria dos alunos entrevistados acreditavam que o ensino adquirido na escola não era suficiente para disputar uma vaga numa universidade pública ou numa escola militar. Para ela, a grade curricular da escola era defasada se comparada ao ensino particular e federal. E ela afirmava sentir falta do incentivo dos professores.

Indo contra a afirmação dos outros entrevistados, Júlio afirmava que é possível sim ingressar na universidade apenas estudando no colégio público estadual. Diz que os professores são muito qualificados e que o problema, na verdade, seria a falta de interesse dos alunos para com a escola, que era preciso mais dedicação da parte dos alunos. E disse também que seus pais o apoiavam de todas as maneiras para atingir seu objetivo, e que pagariam seu curso sem problemas (seu pai é taxista e sua mãe é empregada doméstica, tendo ambos estudado até o ensino médio).

Para Roberta, aluna que estava em dúvida entre o curso de Jornalismo e o de Relações Internacionais e pretendia entrar para uma universidade pública, o pensamento é totalmente oposto. Quando questionada se a escola seria suficiente, ela vai direto ao ponto:

De forma alguma! Primeiro porque se fosse depender da escola estadual para passar no Enem eu já teria zerado a prova de Física, pois eu não tive aula desde o primeiro ano por não ter professor. Então complica. Esse ano tive que fazer cursinho on-line para poder ver matérias que não foram dadas. Enfim... não é suficiente. (Roberta).

Roberta fez um cursinho on-line para poder complementar a carência que teve no terceiro ano. Para ela, a escola no ano da entrevista atrapalhou mais do que ajudou em relação ao Enem, pois não pôde focar em assuntos exclusivos dele. Logo, ela já estava planejando seus estudos do ano que vem para se preparar melhor para o Enem.

Lorena, outra aluna que pretendia fazer um curso técnico, optou por fazer Enfermagem quando respondia ao questionário. Mas quando fui entrevistá-la, ela disse amar Medicina e que desejava fazer o curso superior. No entanto, considerava-o distante de suas possibilidades naquele momento, e tinha como opção mais próxima o ensino técnico.

Ano que vem eu vou entrar num cursinho técnico de Enfermagem para já ter uma qualificação para trabalhar, arranjar um trabalho melhor. Porque já que eu não tenho ensino técnico eu primeiro vou ter que trabalhar no mercado. Se eu não conseguir de graça eu vou pagar o curso de Enfermagem para mim. (Lorena).

Essa é uma escolha que se repete várias vezes. Girard e Bastide, citados por Bourdieu (2010, p. 47) dizem: "Os objetivos das famílias reproduzem de alguma maneira a estratificação social". Observamos que, muitas vezes, o sonho de um curso mais concorrido, de maior status, está longe, ou nem mesmo é cogitado. Lorena ainda tinha muito o que pensar sobre quais estratégias adotar. Pretendia começar o curso técnico em 2018, mas já havia começado a trabalhar fora dessa área, num 
mercado. Esperava conseguir encontrar um curso gratuito, mas se tivesse que pagar continuaria trabalhando. Iria tentar o vestibular "até conseguir", mas estudando por conta própria, porque não seria possível pagar o cursinho. Ela também foi mais uma a criticar o fato de que a escola não dava foco nos temas que mais caíam no Enem: acha que o terceiro ano deveria focar mais no exame.

Por último, entrevistamos dois alunos que marcaram em seus questionários que não pensavam em continuar seus estudos, seja via ensino superior, técnico ou outro qualquer. Seu projeto era "arranjar um trabalho". Estes alunos diziam não estar preparados para a universidade e demonstraram não conhecer quase nada acerca desta possibilidade. É provável que nunca tivessem feito esse questionamento anteriormente, ilustrando o que diz Dayrell: "Nas suas experiências no mundo do trabalho não esteve e não está presente a dimensão da escolha, o trabalho sendo encarado como uma obrigação necessária" (DAYRELL, 2003, p. 45).

Quando perguntei sobre algum curso ou área que gostaria de um dia trabalhar, um deles, Carlos, demorou para responder e por fim falou que faria Contabilidade, mas concluiu, rindo, que para isso teria que passar de ano em matemática primeiro. Quando questionado sobre o apoio de sua família, a resposta dele foi a que mais se diferenciou de todas. Nos outros 8 entrevistados, sempre esteve presente em suas falas que recebiam algum tipo de apoio dos pais ou outros familiares, seja um apoio financeiro ou moral, isto é, incentivo. No caso de Carlos, ele foi bem enfático em afirmar que não recebia nenhum tipo de apoio. Ele tinha dois irmãos que também não fizeram faculdade.

\section{Horizontes de expectativas e reprodução social das desigualdades: escola e trabalho}

A importância das percepções dos indivíduos enquanto fator estruturante da realidade social é uma das pedras de toque da sociologia feita a partir do último quarto do século XX (BERGER; LUCKMANN, 1983, p. 173-241). Sem negar a importância da estrutura objetiva de relações dadas, nas últimas décadas tem-se buscado como os indivíduos, em sua vida social, percebem a estrutura das posições, incorporando-a em seu mundo particular de acordo com as suas próprias visões de mundo e produzindo, assim, novas formas de hierarquizar os sujeitos e os objetos.

Nesse sentido, investigar a percepção dos alunos sobre as possibilidades de seu futuro, as suas expectativas, significa pensar como a estrutura de posições objetivas (seja de renda, prestígio ou poder) no interior de uma sociedade se reproduz através dos indivíduos, isto é, como a estrutura se "reproduz", ao dar forma àquilo que os indivíduos creem ser "adequado" aos seus desejos. Os dados apresentados nos indicam dois movimentos dentre os alunos: um certo "rebaixamento" das suas expectativas àquilo que pensam ser adequado a si mesmos; e uma busca por estabilidade e segurança no trabalho. Vamos elaborar esses dois pontos a partir, primeiramente, de uma reflexão sobre a escola em si e, em seguida, de uma interpretação de maior alcance acerca do mundo do trabalho atual.

\section{Ainda a reprodução do sistema de ensino}

A inclusão de um grande contingente de jovens que antes estava fora da escola representou e ainda hoje representa um enorme desafio para toda a comunidade escolar, em especial para gestores e professores. Como aponta Sposito (2005), as escolas passam a ter em seu interior não apenas os "herdeiros" do capital cultural, isto é, jovens brasileiros das classes mais favorecidas, mas jovens que sofrem cotidianamente os conflitos da radical desigualdade social brasileira.

Vale a reflexão sobre até que ponto realmente há uma escolha de futuro para o jovem de periferia. Quais são as referências de sucesso dentro do lugar onde vivem? Quais as limitações geográficas no bairro em que vivem? E sobre os modos de constituição de subjetividade desses jovens, 
quais são as trajetórias de aceitação, daqueles que continuam a viver, trabalhar no mesmo bairro? $\mathrm{E}$ as trajetórias de subversão, daqueles que vão estudar longe de casa, e ocupam novos espaços na cidade? Como assinala MacDonald et al. (2005), os caminhos tomados e as oportunidades que aparecem na vida são muito influenciadas pelo lugar onde nascem e vivem e que definem, de saída, sua posição numa estrutura de classe. Corroborando com essa ideia, em Pais (2016) também se compreende que a trajetória é cruzada pelos conceitos de vida familiar, escolar, profissional, e que essas esferas estão conectadas entre si. No cotidiano escolar, dentre os alunos é comum ouvir um discurso de que ao terminar a escola, os rapazes têm três opções de futuro: trabalhar de mototáxi, barbeiro ou "entrar para o tráfico"; enquanto as meninas ou serão designer de sobrancelhas ou vendedoras de doce. Como coloca Silva (2005, p. 20), "não há estímulos a empregos de qualidade". Portanto, muitos desses jovens já têm essas funções no horizonte.

A partir dos questionários e entrevistas, mas também de conversas informais com alunos ao longo dos últimos anos, nos parece merecer destaque o fato de que a opção pela vida militar vem crescendo cada vez mais. E o que despertou mais interesse e surpresa foram os motivos para esse desejo: além daqueles que já há bastante tempo sonham em ser militares, ou enxergam na vida militar uma certa retidão, uma legitimidade estética - no interior de uma subjetividade que valoriza o militarismo como estilo de vida -, muitos outros alunos que estão optando por esse caminho acreditam essa ser uma saída para, como alguns alunos declararam, "ter estabilidade e segurança", "ter um emprego", "ter um salário em dia”, já que vivemos, já há alguns anos, uma crise no mercado de trabalho (DRUCK, 2021). Os planos para cursar uma faculdade ficam para depois de conseguir se estabilizar economicamente ${ }^{6}$.

Remontando à discussão sobre desigualdade e poder na educação, outro aspecto observado no discurso desses jovens de periferia, tanto no que procura um concurso militar e tem como objetivo maior realizar a prova para sargento, quanto naqueles que procuram um curso menos concorrido no vestibular pois acreditam não estarem preparados para disputar uma vaga de um curso concorrido com um aluno de cursos pré-vestibular, é uma percepção de que há um "limite" de até onde ele pode almejar: para eles, não se deve desejar o impossível. Um exemplo significativo ocorreu durante uma das entrevistas realizadas, quando, perguntando para alguns alunos do primeiro sobre o que gostariam de tentar no vestibular, uma estudante disse que iríamos rir, mas que ela gostaria de fazer Medicina. É como se esse caminho não fosse para ela; ela sabe que deseja o "impossível”. Como assinala Bourdieu (2010, p. 47): o "isso não é para nós" acaba por criar uma noção de "impossibilidade" em relação à busca por determinados objetivos.

Como aponta também José Machado Pais (2016), haverá um embate entre o querer e o poder na vida do jovem. Portanto, por hora, abre-se mão do que é o verdadeiro desejo, escolha, para buscar algo que satisfaça mais rapidamente e seguramente o que é urgente e básico, para que então num futuro onde, espera-se, haverá mais estabilidade, o desejo tenha alguma possibilidade de ser cumprido. Porém, é difícil dizer que esse caminho será traçado de acordo com o imaginado. E tudo isso numa sociedade que exige a formação contínua dos indivíduos. "É nestas encruzilhadas de vida que se joga a vida e o futuro da mesma" (PAIS, 2016, p. 304).

Portanto, se, como destacaram Scalon e Oliveira (2012), os alunos das camadas menos favorecidas veem na educação formal, de maneira mais intensa do que os alunos de classe média, 
um meio de ascensão social, então a desorganização pedagógica percebida aparece para eles como um forte obstáculo ao seu sucesso, um problema objetivo que produz a sensação de que devem reduzir suas expectativas ao plausível; isto é, produz um efeito de reprodução das desigualdades na medida em que reduz o campo daquilo que esses alunos se permitem querer para si.

\section{Uma interpretação politicista e trabalhista para o rebaixamento das expectativas}

Assim como a análise da produção da indignação dentre trabalhadores no ambiente de trabalho não pode prescindir de pelo menos esboçar os determinantes da subjetividade do trabalhador que se encontram no "exterior" da atividade laboral propriamente dita - como a família, o local de moradia, o percurso escolar, em suma, tudo aquilo que constitui a "experiência de classe" (THOMPSON, 1987) de determinado indivíduo -, tampouco é possível analisar as expectativas dos alunos baseando-se exclusivamente na sua experiência no ambiente escolar. Nesse sentido, nesta seção traremos um argumento de maior nível de abstração; trata da produção social, no nosso contexto nacional, de determinado "horizonte de expectativas" dentre as camadas menos favorecidas da população brasileira, justamente o objeto que estamos analisando aqui.

Wanderley Guilherme dos Santos (2006), ao tomar a produção de expectativas como objeto de pesquisa, e inspirado pela sociologia política de Alexis de Tocqueville se pergunta se seria possível, no Brasil "um processo de expectativas crescentes, que se desloca a ritmo superior ao do progresso real" (2006, p. 152), e que terminaria por produzir um forte abalo das instituições políticas, sob o paradigma da Revolução Francesa, analisada por Tocqueville (1997). Dada a enorme desigualdade no país, o sentimento de se estar privado de algo que se acredita que se "deveria" ter ${ }^{7}$ poderia, em tese, permitir a constituição de fortes movimentos sociais. A questão é que, historicamente, isto não ocorreu no país na proporção de suas desigualdades. Por quê? Responde o autor que isto se deu por conta de um processo de "rebaixamento permanente" do "horizonte de expectativas" das camadas populares, em função dos altos custos da mobilização reivindicatória. A extrema violência com que são tratados os movimentos sociais no país - mesmo aqueles mais organizados, como os sindicatos e as organizações estudantis - tenderiam a produzir expectativas de ascensão social cada vez mais conformadas ao plausível, inviabilizando disposições de satisfação de expectativas posicionadas muito além do plausível, isto é, que seriam consideradas "utópicas". O mesmo movimento produziria grande tolerância social à desigualdade pelos menos favorecidos. De fato, no Brasil, a pesquisa sociológica indica que os mais pobres tendem a ser "mais" tolerantes com a desigualdade que os mais ricos (CARDOSO, 2004, p. 157).

Embora voltado para a compreensão da produção de movimentos sociais que visassem a redução da desigualdade distributiva no país - movimentos contra o arrocho salarial, a alta de preços e a carestia, a favor da ampliação de direitos trabalhistas e sociais, etc. -, este modelo de dinâmica política pode iluminar também algumas respostas que obtivemos dos alunos pesquisados. Afinal, as afirmações coletadas apontam não só para a existência de expectativas ajustadas à condição nas quais eles mesmos se percebem, mas também para momentos específicos de rebaixamento dessas expectativas na interação com os outros - no caso, com o entrevistador ${ }^{8}$. Isto é, os alunos não apenas parecem incorporar a estrutura de posições na qual se percebem inseridos, produzindo projeções de plausibilidade de suas escolhas para o futuro (de modo a remover delas o "impossível", o "utópico"), mas também as "atualizam" constantemente, em seu cotidiano, no qual a escola tem um papel fundamental.

7 Sentimento que ele denomina de "privação relativa" (2006, p. 145).

8 Pensamos aqui, por exemplo, na aluna que imaginou que o entrevistador riria de seu desejo de entrar em um curso de Medicina. 
Mesmo sendo a posição de classe em que esteja elemento fundamental nessa dinâmica, sua trajetória não é simplesmente um reflexo dessa posição, pois a percepção do indivíduo sobre a sua posição, assim como suas expectativas, podem variar conforme sua atualização cotidiana, donde a importância da experiência escolar: se a reação do entrevistador - que também era o seu professor - à aluna que queria cursar Medicina fosse a de um sorriso sarcástico, a interação contribuiria para tornar o desejo ainda mais implausível.

Quanto ao segundo achado empírico - o desejo de segurança e estabilidade profissional, do qual a escolha pela carreira militar é a melhor ilustração -, podemos interpretá-lo enquanto uma escolha pragmática, ainda mais se acrescentarmos, de sua parte, a percepção da precariedade das posições oferecidas atualmente pelo mercado de trabalho brasileiro, já há anos em crise. O sentido geral desse mercado no país hoje é o da precarização do emprego formal, sobretudo por meio da terceirização das atividades (ANTUNES, 2018, p. 169) e aumento da informalidade (FILGUEIRAS, 2019, p. 34), precarização esta que, embora já estivesse ocorrendo desde a década de 90 , ganhou impulso dramático a partir da aprovação da Reforma Trabalhista (KREIN, 2018), em 2017, e cujo ímpeto no meio político não parece ter arrefecido ainda?

Como colocado por alguns entrevistados, a escolha por uma carreira militar significa a busca de estabilidade de rendimento, e só a partir da conquista desta estabilidade que os alunos passam a projetar para si trajetórias mais ambiciosas: cursar o ensino superior, qualificar-se por meio de outros cursos, etc. Em suma, não buscam o militarismo tanto por seus "valores" intrínsecos (embora existam os que o façam por isso), mas enquanto oportunidade de independência individual e estabilidade financeira; justamente dois atributos que o mercado de trabalho no país vem oferecendo cada vez menos.

\section{Considerações finais}

Este artigo buscou investigar a influência da experiência escolar dos alunos da rede pública estadual de ensino nas suas expectativas e perspectivas de futuro, sejam profissionais ou educacionais. Em seu conjunto, os dados apresentados ecoam uma literatura que aponta para o caráter fortemente reprodutivista da experiência escolar desses alunos.

Ao serem entrevistados, os alunos deixam claro que estão cientes desse estado de coisas e, portanto, aqueles que possuem expectativas profissionais e/ou acadêmicas que exigem maior investimento claramente não percebem em sua escola o apoio a esses projetos. Projetam, assim, planos individuais de busca de continuidade na trajetória desejada.

Isso não significa afirmar que avaliam as probabilidades de sucesso desses projetos a partir apenas de variáveis individuais: percebem o descompasso de sua formação em relação à formação de alunos de outras escolas, cujo referencial de "competitividade" é o Enem, prova para a qual a sua escola não oferece nenhuma preparação específica. Interpretam que estão em desvantagem, uma desvantagem sentida individualmente, mas avaliada enquanto um problema que tem suas origens para além de si próprios, do indivíduo, e que se situa no nível institucional da qualidade escolar. Nesse sentido, podemos afirmar, em concordância com a bibliografia levantada, que os alunos tendem a fazer escolhas para seu futuro que acreditam ser plausíveis para a qualidade escolar dentro da qual eles se veem se formando.

Enquanto instituição, a escola pesquisada parece ser indiferente ao Exame, atuando como se o seu papel com os alunos concluintes terminasse no momento em que eles recebessem o diploma

9 Vide a permanente disposição desregulamentadora do governo Bolsonaro. Disponível em: https://www1.folha.uol.com.br/mercado/2020/01/pacotaco-de-pecs-altera-de-lei-trabalhista-a-medidas-sociais.shtml?origin=folha. Acesso em: 20 maio 2020. 
escolar: ela não parece se colocar o objetivo de fazer o aluno acessar a universidade. Uma ilustração disso é o fato de a única referência ao Enem ser um cartaz afixado em mural com a data de inscrição. Por fim, destacamos um segundo ponto, que está ligado a este, mas não diretamente, que é a escolha dos alunos pela carreira militar. Como exposto acima, a sociologia do trabalho brasileira tem se dedicado, nos últimos anos, a explicitar o caráter precarizador das reformas legislativas que vêm sendo aprovadas. Partindo dessa avaliação, a escolha de parte dos alunos pelo militarismo evidencia, em primeiro lugar, uma avaliação crítica "nativa" do sentido das mudanças nas relações gerais de trabalho e, em segundo lugar, a adoção de uma posição individual que busca se esquivar dos problemas derivados dessa inserção precária no mercado de trabalho: o militarismo é buscado explicitamente por seu caráter "estável", pela oportunidade de "ter um fixo" que possibilite tornar mais elásticas as oportunidades de ascensão social. Nesse sentido, tal escolha aponta para um desejo de "não reprodução" do momento presente, contrariamente àquilo que, intuitivamente, poderíamos interpretar como uma escolha "conservadora".

Em suma: é possível afirmar, com a literatura acerca da dinâmica da reprodução social (escolar e política) mobilizada, que há um rebaixamento do horizonte de expectativas dos alunos, em função da "percepção de indiferença institucional" da escola pública estadual com relação ao seu futuro, que os deixa presas da resignação resultante de uma avaliação pragmática das suas possibilidades individuais; mas também é possível perceber, na busca por uma estabilidade financeira, o desejo de superar a sua condição por meio de expediente de ação individual - preparar-se para conseguir entrar na carreira militar -, mas que possui um lastro institucional em outro órgão estatal: as Forças Armadas. Assim, a percepção dos alunos acerca do déficit de seu capital escolar está diretamente relacionada à sua experiência escolar, "na mesma medida em que acreditam na educação como meio por excelência de ascensão social"; déficit este que procuram amenizar, de um lado, rebaixando suas expectativas de futuro e, de outro, montando estratégias de trajetória que se apoiam em instituições que, de fato, oferecem lastro institucional para a persecução de seus objetivos.

\section{Referências}

ANTUNES, Ricardo. O privilégio da servidão: o novo proletariado de serviços na era digital. São Paulo: Boitempo, 2018. BERGER, Peter L.; LUCKMANN, Thomas. A construção social da realidade: tratado de sociologia do conhecimento. Petrópolis: Vozes, 1983.

BOURDIEU, Pierre. A escola conservadora: as desigualdades frente à escola e à cultura. In: NOGUEIRA, Maria Alice; CATANI, Alfredo (org.). Escritos de educação. 11. ed. Petrópolis: Vozes, 2010. p. 39-64.

CARDOSO, Adalberto. Desigualdade, injustiça e legitimidade: uma investigação empírica sobre aspectos da sociabilidade brasileira. In: SCALON, Celi. Imagens da desigualdade (org.). Belo Horizonte: Ed. UFMG, 2004. p. 115-175.

CENTRO DE ESTUDOS SINDICAIS E DE ECONOMIA DO TRABALHO (CESIT). Contribuição crítica à reforma trabalhista. Campinas: UNICAMP/CESIT, 2017.

DARDOT, Pierre; LAVAL, Christian. A nova razão do mundo. São Paulo: Boitempo Editorial, 2017.

DAYRELL, Juarez. O jovem como sujeito social. Revista Brasileira de Educação, Rio de Janeiro, n. 24, p. 40-52, set./dez. 2003.

DAYRELL, Juarez. A escola "faz" as juventudes? Reflexões em torno da socialização juvenil. Educação e sociedade, Campinas, v. 28, n. 100, p. 1105-1128, out. 2007.

DAYRELL, Juarez; LEÃO, Geraldo; BATISTA, Juliana dos Reis. Juventude, projetos de vida e ensino médio. Educação \& Sociedade, Campinas, v. 32, n. 117, out./dez. 2011.

DRUCK, Graça. A tragédia neoliberal, a pandemia e o lugar do trabalho. O social em questão, Rio de Janeiro, ano 24, n. 49 , p. 11-34, jan./abr. 2021. 
FILGUEIRAS, Vitor Araújo. As promessas da Reforma Trabalhista: combate ao desemprego e redução da informalidade. In: FILGUEIRAS, Vitor Araújo; KREIN, José Dari; OLIVEIRA, Roberto Véras de (org.). Reforma trabalhista no Brasil: promessas e realidade. Campinas: Curt Nimuendajú, 2019. p. 13-52.

GERALDI, João Wanderley. A Aula como Acontecimento. São Paulo: Pedro \& João Editores, 2015.

KREIN, José Dari. O desmonte dos direitos, as novas configurações do trabalho e o esvaziamento da ação coletiva: consequências da reforma trabalhista. Tempo Social, Campinas, v. 30, n. 1, p. 77-104, abr. 2018.

MACDONALD, Robert et al. Growing Up in Poor Neighbourhoods: The Significance of Class and Place in the Extended Transitions of 'Socially Excluded'Young Adults. Sociology, Reino Unido, v. 39, n. 5, p. 873-891, 2005.

PAIS, José Machado. Conclusão. In: PAIS, José Machado. Ganchos, tachos e biscates: jovens, trabalho e futuro. Portugal: Edições Machado, 2016. p. 299-317.

SANTOS, Wanderley Guilherme dos. Horizonte do desejo: instabilidade, fracasso coletivo e inércia social. Rio de Janeiro: Ed. FGV, 2006.

SCALON, Celi; OLIVEIRA, Pedro Paulo de. A percepção dos jovens sobre desigualdades e justiça social no Brasil. Interseções, Rio de Janeiro, v. 14, n. 2, p. 408-437, dez. 2012.

SILVA, Jailson de Souza. Considerações sobre a juventude e violência urbana. Eco-Pós, Rio de Janeiro, v. 8, n. 1, p. 13-23, jan./jul. 2005.

SPOSITO, Marília Pontes. Algumas reflexões e muitas indagações sobre as relações entre juventude escola no Brasil. In: ABRAMO, Helena Wendel; BRANCO, Pedro Paulo Martoni (org.). Retratos da juventude brasileira: análises de uma pesquisa nacional. São Paulo: Instituto Cidadania: Fundação Perseu Abramo, 2005. p. 87-129.

THOMPSON, Edward Palmer. A formação da classe operária inglesa. Volume 1: A árvore da liberdade. São Paulo: Paz e Terra, 1987.

TOCQUEVILLE, Alexis de. O antigo regime e a revolução. Brasília, DF: Editora Universidade de Brasília, 1997.

Data de submissão: 29/01/2021

Data de aceite: 09/02/2021 